\title{
A novel endoloop pretest to treat severe gastroesophageal reflux disease symptoms before anti-reflux mucosectomy
}

A 44-year-old man with a 6-year history of gastroesophageal reflux disease (GERD; score of 30 on GERD questionnaire) underwent an upper gastrointestinal (GI) endoscopy, which revealed esophagitis (Los Angeles grade A). After failure of maximal medical therapy for GERD, the patient underwent a new minimally invasive, reversible endoscopic treatment, with the aim of predicting whether his symptoms could be alleviated, in order

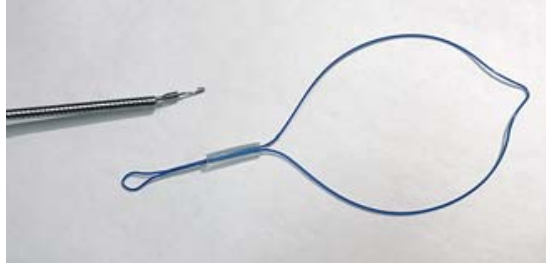

> Fig. 1 The LeCamp endoloop. to ultimately decide whether to undergo irreversible surgery or endoscopic treatment.

A novel LeCamp endoloop (Leo Medical, China) ( Fig. 1) was inserted into the gastric cardia using forceps passed through a single-channel endoscope ( Fig.2a). After adjustment of the location and angle of the endoloop, it was anchored onto the edge of the gastric cardia with a clip ( $\mathbf{F i g} \mathbf{2} \mathbf{b}$ ) and another one or two clips were inserted to hold the opposite side of endoloop about halfway round the circumference ( $\triangleright$ Fig. $2 \mathbf{c}$ ). The hook was then connected with the endoloop ( $\mathbf{F i g . 2 d}$ ), which was tightened with a slight pulling together of all the clips ( $\triangleright$ Fig.2e). The patient did not experience any pain and was safely discharged the same day.
After the treatment, the patient showed significant improvement in his symptoms with a score of 4 points on the GERD questionnaire and was able to discontinue daily use proton pump inhibitors. At 1-month follow-up, the patient complained that the symptoms were gradually re-appearing, repeat upper $\mathrm{Gl}$ endoscopy revealed the endoloop and the clips had dropped off. After the patient had given his consent, anti-reflux mucosectomy (ARMS) was performed using standard endoscopic submucosal dissection [1]. At the 3-month followup, he reported significant reduction in GERD questionnaire scores and his upper Gl endoscopy showed a tight gastroesophageal junction (> Fig. 3 ).

In this patient, we used a novel pretest to narrow the gastric cardia before he underwent ARMS, which suggests that this
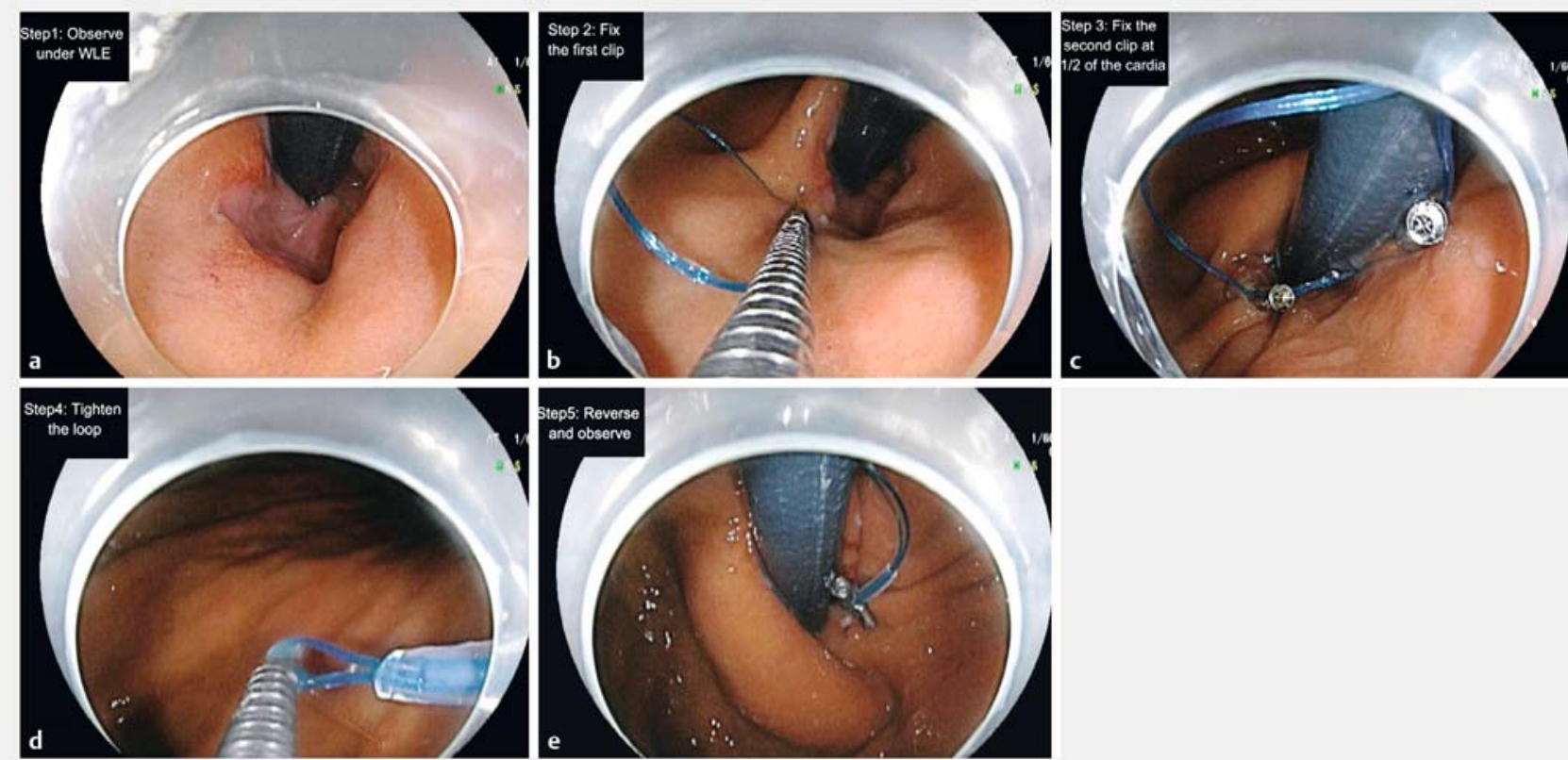

Fig. 2 White-light endoscopy views showing: $\mathbf{a}$ the gastric cardia; $\mathbf{b}$ the endoloop being fixed with the first clip using forceps passed through a single-channel endoscope; $\mathbf{c}$ a second clip being applied halfway around the circumference of the cardia; $\mathbf{d}$ the hook being connected to tighten the endoloop; e the gastric cardia in retroflexed view after the endoloop has been fixed and tightened. 


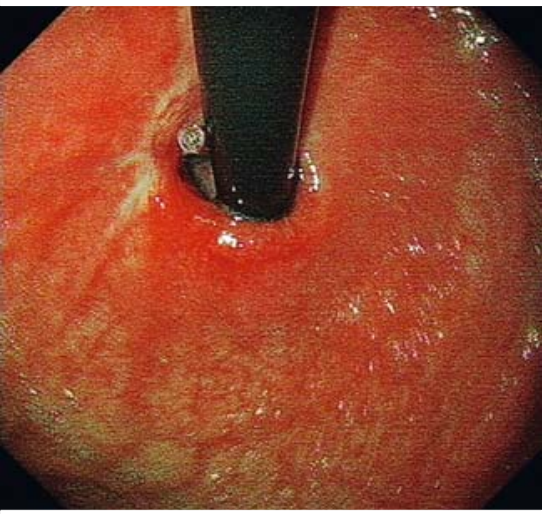

- Fig. 3 Endoscopic appearance 3 months after undergoing anti-reflux mucosectomy showing a tight gastroesophageal junction.

new technique may be a simple and reversible method to control symptoms temporarily in GERD patients, while they decide whether to undergo irreversible surgery or endoscopic treatment.

Endoscopy_UCTN_Code_CCL_1AB_2AC_3AC

Competing interests

None

The authors

\section{Min Min, Yan Liu}

Department of Gastroenterology and Hepatology, Affiliated Hospital of Academy of Military Medical Sciences, Beijing, China

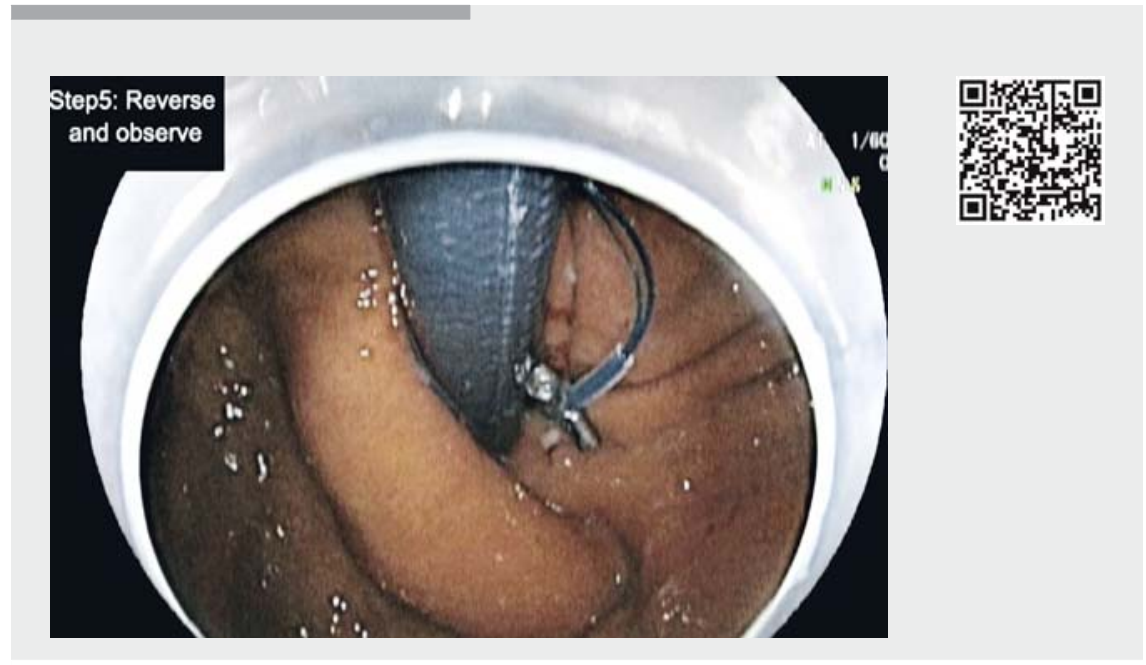

Video 1 A novel endoloop pretest to treat severe gastroesophageal reflux disease symptoms before anti-reflux mucosectomy in a 44-year-old man.

Corresponding author

\section{Yan Liu, MD, PhD}

Department of Gastroenterology and Hepatology, Affiliated Hospital of Academy of Military Medical Sciences, Beijing, 100071, China

Fax: +86-10-66947473

13911798288@163.com

\section{Reference}

[1] Inoue $\mathrm{H}$, Ito $\mathrm{H}$, Ikeda $\mathrm{H}$ et al. Anti-reflux mucosectomy for gastroesophageal reflux disease in the absence of hiatus hernia: a pilot study. Ann Gastroenterol 2014; 27: 346 351

\section{Bibliography}

DOI https://doi.org/10.1055/a-0861-9849

Published online: 12.4.2019

Endoscopy 2019; 51: E193-E194

(c) Georg Thieme Verlag KG

Stuttgart · New York

ISSN 0013-726X

ENDOSCOPY E-VIDEOS
https://eref.thieme.de/e-videos
techniques in gastroenterological
endoscopy. All papers include a high
quality video and all contributions are
freely accessible online.
This section has its own submission
website at
https://mc.manuscriptcentral.com/e-videos

